\title{
EL IMPACTO DE LA PANDEMIA EN EL SEGURO. PANORAMA EN ARGENTINA*
}

\section{THE IMPACT OF THE PANDEMIC ON INSURANCE. OUTLOOK IN ARGENTINA}

\author{
MARÍA FABIANA COMPIANI* \\ Fecha de recepción: 30 de abril 2020 \\ Fecha de aceptación 15 mayo 2019 \\ Disponible en línea: 30 de junio 2020
}

Para citar este artículo/To cite this article

Compiani, María Fabiana. El impacto de la pandemia en el Seguro. Panorama en Argentina, 52 Rev.Ibero-Latinoam.Seguros, 105-120 (2020). https://doi.org/10.11144/Javeriana.ris52.ipsp

Doi: 10.11144/Javeriana.ris52.ipsp

\footnotetext{
* Artículo de reflexión, desarrollado a partir de la columna de opinión publicada en la Ley el 20/04/20 y del reporte de la sección nacional publicado el 04/05/20 en el sitio web de AIDA https://aidainsurance.org/ news/impact-of-covid-19-insurance-issues-in-various-countries- 2020-04-06.

** Abogada de la Universidad del Museo Social Argentino. Realizó curso de posgrado de "Seguro contra la Responsabilidad Civil", de la Universidad de Buenos Aires. Doctoranda en Derecho Privado de la Universidad de Ciencias Empresariales y Sociales. Profesora de la Facultad de Derecho y Ciencias Sociales de la Universidad de Buenos Aires. Presidente de la Asociación Argentina de Derecho de Seguros. Contacto: fabianacompiani@gmail.com.
} 


\title{
RESUMEN
}

El artículo revisa el impacto que la pandemia por coronavirus ha tenido en los diversos riesgos objeto del contrato de seguro en Argentina. Para ello, se realiza una semblanza tanto de las medidas tomadas por la autoridad pública como el estado de situación del sector asegurador en el país. Asimismo, se efectúa una breve síntesis de los remedios previstos en la ley especial y en la legislación general.

Palabras claves: Pandemia. Aislamiento preventivo y obligatorio. Contrato de seguro. Riesgos cubiertos. Agravación y disminución del riesgo. Prima. Caso fortuito.

\begin{abstract}
The article reviews the impact of the coronavirus pandemic that it has had on the various risks covered by the insurance contract in Argentina. For this, a semblance is made of both the measures taken by the public authority and the state of affairs of the insurance sector in the country. Likewise, a brief synthesis of the remedies provided in the special law and in the general legislation is made.
\end{abstract}

Keywords: Pandemic. Preventive and compulsory isolation. Insurance contract. Covered risks. Aggravation and decrease of risk. Cousin. Act of God.

\section{SUMARIO}

1. Introducción. 2. El seguro automotor frente a la pandemia. 3. La reacción del sistema de seguros de riesgos del trabajo. 4. La cuestión en los seguros de riesgos patrimoniales. 5. El covid-19 en los seguros de personas. 6. La disminución y agravación del riesgo: su impacto en la prima. 7. Los remedios previstos en el Derecho Privado frente a un evento fortuito. 8. Algunas conclusiones provisionales. Bibliografía. 


\section{INTRODUCCIÓN}

A poco menos de dos meses de la declaración por parte de la Organización Mundial de la Salud de la pandemia por COVID-19, me propongo reseñar el impacto que ha tenido en el seguro hasta el presente en Argentina, señalando que su evolución obligará a revisar estas líneas a medida del desarrollo de los acontecimientos.

En la actualidad, el Poder Ejecutivo se apresta a dictar una nueva ampliación del aislamiento preventivo obligatorio que comenzó el 20 de marzo y que mereció dos extensiones anteriores. La Argentina atraviesa, por tanto, el día 51 de la cuarentena: tiene hasta el momento más de 5600 personas contagiadas y 293 víctimas fatales. Por su parte, los recuperados superan los 1650 casos $^{1}$.

Cierto es que en la mayor área geográfica del país se ha dispuesto el ingreso a la denominada fase cuatro con un retorno controlado a las actividades productivas y de comercio, pero manteniendo la prohibición de la actividad educativa presencial en todos los niveles, así como la realización de eventos masivos. Sin embargo, la jurisdicción de la Ciudad Autónoma de Buenos Aires y sus cercanías, el conurbano bonaerense, donde habitan aproximadamente 10 millones de personas (poco menos de $1 / 4$ de la población total del país), sigue bajo un régimen de cuarentena estricta ${ }^{2}$, sólo excepcionada para las actividades denominadas esenciales (las que por cierto han ido creciendo con cada nueva extensión hasta un número cercano a medio centenar). ${ }^{3}$ Recién la semana entrante se habilitará la atención de comercios de cercanía dedicados a unos pocos rubros en exceso de los destinados a alimentación, farmacia y limpieza autorizados desde inicio. La actividad aseguradora aún no fue excepcionada, como

\footnotetext{
1 Diario La Nación 9 de mayo de 2020: https://www.lanacion.com.ar/sociedad/coronavirus-hoy-minutominuto-novedades-argentina-mundo-nid2340949.

2 El Art. 2 del Decreto 297/20 del 20 de marzo dispuso que "Durante la vigencia del 'aislamiento social, preventivo y obligatorio', las personas deberán permanecer en sus residencias habituales o en la residencia en que se encuentren a las 00:00 horas del día 20 de marzo de 2020, momento de inicio de la medida dispuesta. Deberán abstenerse de concurrir a sus lugares de trabajo y no podrán desplazarse por rutas, vías y espacios públicos, todo ello con el fin de prevenir la circulación y el contagio del virus COVID-19 y la consiguiente afectación a la salud pública y los demás derechos subjetivos derivados, tales como la vida y la integridad física de las personas", la misma norma previó que aún en aislamiento las personas "podrán realizar desplazamientos mínimos e indispensables para aprovisionarse de artículos de limpieza, medicamentos y alimentos".

3 La nómina de las excepciones al aislamiento que dispuso el Art. 6 fue amplia, quedaron exceptuadas del cumplimiento del "aislamiento social, preventivo y obligatorio" y de la prohibición de circular, las personas afectadas a las actividades y servicios declarados esenciales en la emergencia, según se detalla en los 24 incisos de la norma, entre los que se encuentran "...6. Personas que deban atender una situación de fuerza mayor...”, “...16. Recolección, transporte y tratamiento de residuos sólidos urbanos, peligrosos y patogénicos...”, “...18. Transporte público de pasajeros, transporte de mercaderías, petróleo, combustibles y GLP...”, “...19. Reparto a domicilio de alimentos, medicamentos, productos de higiene, de limpieza y otros insumos de necesidad..." y las diversas actividades que se sumaron en las ampliaciones subsiguientes (venta de materiales de la construcción, actividades forestales y mineras, curtiembres, aserraderos y fábricas de productos de madera, colchones, maquinaria vial y agrícola, exportaciones de productos ya elaborados e importaciones esenciales) e incluso las mujeres y personas del colectivo LGTTBI que deban realizar denuncias o solicitar asistencia por situaciones de violencia.
} 
tampoco la de los productores y brokers y sólo se liberó, bajo protocolo sanitario, la de los liquidadores de siniestros ${ }^{4}$.

La producción del sector asegurador argentino (de 186 aseguradoras) es de poco menos del 3\% del PBI y los seguros más relevantes son los obligatorios, entre los cuales, los de mayor volumen son el de responsabilidad civil automotor y el de riesgos del trabajo (concentran el $74 \%$ de la producción de los ramos Patrimoniales y el $62 \%$ del total de las primas emitidas por toda la industria). En ambos ramos resulta visible la disminución del riesgo producto de la cuarentena obligatoria.

Desde otra perspectiva, no debe dejar de advertirse que la crisis ha afectado severamente las inversiones de las aseguradoras, fundamentalmente por la caída en el valor de los activos financieros y no financieros. Precisamente, la industria del seguro en forma directa o indirecta es tenedora de casi el $70 \%$ de los títulos públicos del país 5 . Ante esta situación la Superintendencia de Seguros de la Nación, órgano de control de la actividad, dispuso la prórroga para la presentación de los balances correspondientes al trimestre enero-marzo de 2020 para todas las aseguradoras. A ello se agregan los problemas causados por la endémica inflación, la caída de la producción en términos reales, el crecimiento de los gastos, la destrucción de la tarifa y la consecuente erosión de los resultados técnicos.

Es este el escenario es que revisamos el impacto de la pandemia en los distintos ramos del seguro.

\section{EL SEGURO AUTOMOTOR FRENTE A LA PANDEMIA}

La cobertura en materia de seguro automotor puede comprender una pluralidad de riesgos y su contenido resulta uniforme y predispuesto por la autoridad de control mediante una póliza que contiene no sólo el seguro obligatorio de responsabilidad civil, sino también el voluntario y los riesgos de incendio, robo y hurto, así como daños al vehículo. A todo ello se suman numerosas cláusulas adicionales susceptibles de ser incorporadas por condición particular a las coberturas principales ${ }^{6}$.

No hubo hasta la fecha ninguna resolución de la Superintendencia que modifique la cobertura uniforme en materia de automotores por lo que su contenido es el vigente y emana del texto uniforme ${ }^{7}$. Sin embargo, nada impediría que la autoridad de con-

\footnotetext{
${ }^{4}$ A través de la Decisión Administrativa N ${ }^{\circ} 524$ del Jefe de Gabinete de Ministros del Poder Ejecutivo Nacional, el gobierno nacional exceptuó de cumplir el aislamiento social, preventivo y obligatorio y de la prohibición de circular a los peritos y a los liquidadores de siniestros de las aseguradoras, sean dependientes o no. Esto a los fines de que puedan realizar la liquidación y el pago de los siniestros. De todas maneras, en ningún caso podrán realizar atención al público y todos los trámites deberán efectuarse en forma virtual, incluyendo los pagos.

5 Plate, Guillermo; Sallaberry, Pablo, ex Vicesuperintendente de Seguros y ex Gerente de Asuntos Jurídicos del mismo organismo en http://www.revistaestrategas.com.ar/contenidos/5605/el_costo_del_ seguro_en_el_marco_de_la_pandemia.

${ }_{6}$ Reglamento General de la actividad aseguradora, Resolución SSN n 38.708, Art. 23 inc. 6a).

${ }^{7}$ Circuló como noticia falsa: “Atención. Desde mañana los seguros no van a cubrir las pólizas de autos por
} 
trol dispusiera una modificación de los contratos de seguro vigentes, cuya validez constitucional se encontraría amparada de acuerdo a la doctrina de la Corte Suprema de Justicia de la Nación ${ }^{8}$. En consecuencia, la autoridad pública podría introducir un supuesto de exclusión específica y ello sería formalmente válido en el marco de la emergencia declarada por la Ley $\mathrm{N}^{\circ} 27.541$ dictada en diciembre de 2019, ampliada por el Decreto del Poder Ejecutivo de comienzos del mes de marzo de este año 260/20 y el ya mencionado 297/20, prorrogado a su vez por tres nuevos decretos.

En este escenario, algunos plantearon la inexistencia de cobertura para los siniestros sucedidos en ocasión de la violación de la prohibición de circular con los vehículos. ${ }^{9}$ Por nuestra parte, sostuvimos que la subsistencia de la cobertura en la medida que no tuvieran lugar alguna de las exclusiones específicas existentes en el texto uniforme: culpa grave (por ejemplo, si el siniestro acaece en razón que el asegurado intente evadir un retén sanitario o de seguridad, o cuando el vehículo fuere confiscado por la autoridad pública, o resulte partícipe en tumultos populares o mientras forme parte en certámenes de velocidad, o mientras sea conducido bajo la influencia de uso de drogas y/o alcohol, etc. $)^{10}$.

Las conclusiones alcanzadas se fundan en un principio liminar del Derecho de Segu$\operatorname{ros}^{11}$ : se encuentra cubierto todo aquello que no fuera ni expresa ni implícitamente excluido $^{12}$. Al no existir una exclusión derivada de pandemia, ni surgiendo ella implícitamente de la descripción del riesgo asegurado, no cabe señalar sino que el siniestro se encuentra cubierto.

Téngase presente que el aislamiento puede ser excepcionado en primer lugar a los fines de la compra de lo necesario en materia de alimentación, farmacia y limpieza en negocios de cercanía (lo podría efectuarse por cualquier medio: caminando, en bicicleta, en motocicleta o trasladándose en un automotor). A ello se suman las numerosas excepciones al aislamiento dispuestas por el mismo decreto que la ordenó y los sucesivos que la extendieron en el tiempo y duplicaron aquellas.

\footnotetext{
cualquier siniestro que suceda, violando el decreto de aislamiento solidario social obligatorio (sic). Si no puede justificar el motivo por el cuál circulaba, no lo va a cubrir por ser falta grave del asegurado. Avisar a todos los conocidos para que luego no sufran las consecuencias". Ante ello, la SSN emitió un comunicado en el que señala que "toda normativa, circular y/o resolución será comunicada de manera oficial y a través de nuestros canales de comunicación verificados, página web, argentina.gob.ar/ssn y redes sociales de la SSN, Twitter, Instagram y LinkedIn" (https:/www.argentina.gob.ar/noticias/comunicado-sobre-el-segurode-vehiculos-automotores-yo-remolcados).

8 Fallos: 247:121; 324:754.

9 El presidente de la Cámara de Diputados de la Nación, Sergio MASSA, se hizo eco de ello: https://agenciafe. com/nota/319648-Advierten-sobre-una-fake-news-sobre-segurosde-los-autos.

${ }_{10}$ Compiani, María Fabiana. "El seguro frente a la pandemia", en el diario La Ley del 20.04.20, p. 1.

11 Halperín, Isaac. "Seguro", $3^{\mathrm{a}}$ ed. actual. y ampl. por Barbato, Nicolás H., Buenos Aires: Depalma, p. 955.

12 Compiani, Maria Fabiana. "Las exclusiones de cobertura en el seguro automotor", RCyS, 2015, III, 225: "La existencia de delimitaciones de cobertura no deriva, pues, del arbitrio o de la discrecionalidad del asegurador, sino de la necesidad creada por la presunción de que se encuentra cubierto todo lo que no se halle excluido, propio del principio de especialidad de la mayor parte de los seguros (incendio, robo, responsabilidad civil, etc.)".
} 
En consecuencia, a la inexistencia de una exclusión para atrapar el supuesto de la prohibición de circulación de pandemia, se suman las excepciones a la prohibición de circulación, que son numerosas y crecientes, lo que tornaría en la práctica muy difícil de aprender como supuesto de violación del mentado impedimento.

Sólo con relación al riesgo de daños, la exclusión 27 reza que no se encuentra cubierto el vehículo asegurado cuando no se encuentre habilitado para circular. Sin embargo, la hipótesis fue introducida para un supuesto diferente: vehículos que carezcan de las autorizaciones y/o habilitaciones técnicas para circular. Aún para ese riesgo específico, forzando la interpretación, su aplicación exigiría al asegurador aportar la difícil prueba de que el asegurado se encontraba violando la prohibición legal al momento de circular.

En cambio, como señalamos, si el daño fuera causado mientras la autoridad pública lo requisó ${ }^{13}$, la exclusión expresa que contiene la cobertura uniforme resultaría aplicable. A ello se suman el resto de los supuestos y, en especial, la culpa grave si se dan sus presupuestos. Con relación a ella, entiendo no sería suficiente para configurarla la circulación en situación prohibida, resultando necesario que exista relación de causalidad adecuada entre la exclusión y el acaecimiento del siniestro.

En nuestro Derecho, para la postura encabezada por el prestigioso maestro Stiglitz ${ }^{14}$, las exclusiones de cobertura que se encuentran sustentadas en conductas antijurídicas de los asegurados, no requieren el análisis de la relación causal con el siniestro. Señala como ejemplo las cometidas en el ámbito de las prohibiciones contenidas en la Ley Nacional de Tránsito $N^{\circ} 24.449$ (ebriedad, falta de licencia habilitante equiparable a licencia vencida o circulación con un número de pasajeros en exceso de las especificaciones de fábrica). Critica algunos pronunciamientos que evidencian una tendencia consistente en analizar si medió relación causal entre la referida conducta y el siniestro, pero silencian que el presupuesto de hecho de la exclusión de cobertura, en el caso, la conducta del asegurado, constituye un obrar antijurídico, entendido ello como una confrontación externa entre la conducta y el ordenamiento jurídico.

En la postura opuesta, el recordado Barbato expresaba que no es sostenible que la mera incorporación a una cláusula de exclusión, de eventuales violaciones en que con relación a leyes, ordenanzas o reglamentos legales, pueda incurrir el asegurado, tenga siempre por efecto indiscutible y automático el colocar una situación de esa índole fuera de la cobertura y para más, por ilicitud de la causa o del objeto del contrato ${ }^{15}$. Es necesario, entonces, que la falta posea entidad suficiente para incidir en el esquema técnico-contractual de manera que influya en la magnitud del riesgo asumido. La misión del seguro no es vigilar el cumplimiento de todo tipo de normas jurídicas sino brindar un amparo contratado a título oneroso.

\footnotetext{
13 El Art. 4 del Decreto 297/20 dispone que “El MINISTERIO DE SEGURIDAD deberá disponer la inmediata detención de los vehículos que circulen en infracción a lo dispuesto en el presente decreto y procederá a su retención preventiva por el tiempo que resulte necesario, a fin de evitar el desplazamiento de los mismos, para salvaguarda de la salud pública y para evitar la propagación del virus".

14 Stiglitz, Rubén S. "La inaplicabilidad del análisis de la relación causal a las exclusiones de cobertura fundadas en actos ilícitos del asegurado", LL 2010-E-999, y por el mismo autor, "Seguro contra la responsabilidad civil y el riesgo automotor", LL 2013-D-1017.

15 Barbato, Nicolás. Exclusiones a la cobertura en el contrato de seguro, ED 136-547.
} 
Ejemplificaba la cuestión con la exclusión de cobertura por carencia de carnet habilitante:

"si el vehículo asegurado está detenido ante un semáforo en rojo y es embestido en la parte posterior por otro rodado, es evidente que ninguna relación causal ha tenido en la producción del accidente el hecho de que el conductor cuente o no con registro habilitante para la conducción. Aplicar aquí la exclusión resultaría antifuncional"'16.

Ahora bien, conviene en este punto formular una precisión. Como es bien sabido, la relación de causalidad y el factor de atribución resultan dos presupuestos independientes de la responsabilidad civil. El primero de ellos reviste un carácter netamente objetivo, mientras que el segundo, tradicionalmente, sólo era de carácter subjetivo (ahora convive con crecientes supuestos de atribución objetiva del deber de responder). La relación causal implica una asignación del resultado, con apoyo objetivo, mientras que la imputación culpable tiene un sentido subjetivo y su juzgamiento se nutre de la culpa o el dolo. La confusión entre estos conceptos no es nueva, sucede que tanto la culpa como la causalidad adecuada se apoyan en un concepto que les es común: la previsibilidad. Pero mientras para la relación causal la previsibilidad será juzgada "in abstracto", para la culpabilidad su análisis será in concreto ${ }^{17}$.

Ahora bien, es cierto que, como lo señala Piaggio, ese distingo entre la previsibilidad subjetiva y objetiva que aparece diáfano en teoría, en la práctica resulta muy dificultoso de discernir y se corre el riesgo de caer en la valoración de la conducta, reapareciendo indebidamente el análisis de la culpa en sede de la causalidad ${ }^{18}$.

Por ello, debe efectuarse un esfuerzo en ceñir el análisis de la exclusión de cobertura y su relación casual con el siniestro, sin ingresar en la valoración de la culpabilidad de la conducta del asegurado en el caso concreto. En el caso, de qué modo el supuesto que constituye culpa grave influyó en el acaecimiento mismo del siniestro (Art. 70 Ley $\left.\mathrm{N}^{\circ} 17.418\right)^{19}$.

Asimismo, habrá que tener en cuenta que quedan excluidos como supuestos de culpa grave “...los actos realizados para precaver el siniestro o atenuar sus consecuencias, o por un deber de humanidad generalmente aceptado" (Art. 70 in fine Ley $\mathrm{N}^{\circ} 17.418$ ).

En resumen, para los siniestros denunciados como ocurridos desde las 0:00 hs. del 20 de marzo último, sólo podrían ser rechazados por el asegurador por las exclusiones de cobertura habituales.

También, con relación al seguro automotor se ha planteado tempranamente la posibilidad de la disminución de prima en consideración a la sensible baja de siniestros, en especial, durante la primera parte de la cuarentena. En el mismo comunicado referido más arriba la Superintendencia de Seguros informó "que no se ha emitido normativa alguna que obligue a las aseguradoras a aplicar descuentos y/o bonificaciones"

\footnotetext{
16 Barbato, Nicolás, "Exclusiones...", cit., nro. 12.

17 Alterini, Atilio A.; Ameal, Oscar J. y López Cabana, Roberto M. Derecho de obligaciones civiles y comerciales, $4^{\mathrm{a}}$ ed. act., Buenos Aires: Abeledo Perrot, 2008, nro. 510, p. 254.

18 Piaggio, Aníbal N. “Azar y certeza en derecho de daños”, especialmente nota 42, ED del 10/5/1993, p. 5.

19 La norma exige que el tomador o beneficiario "provoque" el siniestro.

${ }^{20} \mathrm{Y}$ a renglón seguido "recomienda a la población procurar un asesoramiento directo por parte de las
} 
Según cifras divulgadas por la Agencia Nacional de Seguridad Vial (ANSV), en la Argentina mueren, en promedio, quince personas a diario en siniestros de tránsito. Ese número, al menos del 20 al 24 de marzo, había bajado a dos muertes por día; es decir, un $85 \%$ menos. Según se pudo constatar, algunas compañías redujeron en un $50 \%$ el valor de la cuota por 3 meses o un 30\% en 6 meses a opción del asegurado. Otras redujeron entre 5 y $30 \%$ el valor de las cuotas, a la vez que, para ganar clientela nueva, cotizaron cuotas más reducidas para los que se pasaban de compañía. En muchos casos, los asegurados optaron por reducir en forma temporaria el alcance del seguro o limitarlo a robo y a las contingencias dentro del garaje $\mathrm{e}^{21}$.

Esta última modalidad empero deja sin amparo al asegurado por cualquier evento que surja de la responsabilidad civil derivada del automotor como cosa riesgosa (Art. 1757 CCyCN) y exige que no sólo la cláusula adicional se encuentre mencionada en el anverso de la póliza, sino también resulte incorporada a las condiciones generales de la cobertura a fin que el asegurado se encuentre debidamente informado.

En este contexto, sin embargo, cabe aclarar que no cabría una deducción de prima en el seguro automotor por la sola razón de que la prohibición de circular ha resultado en una menor cantidad de siniestros viales, o en menor cantidad de robos, o de daños e incendios, porque esos riesgos se corren en alguna proporción y en todos los ramos que atañen al rodado. Máxime, tomando en consideración la transitoriedad de la medida y la verificación de que el caudal de circulación ha crecido hasta alcanzar en la actualidad altos niveles fruto seguramente de que también existe temor de viajar en los medios de transporte públicos.

En este aspecto, conviene aclarar que la prima se calcula con relación al riesgo corrido durante toda la vigencia del contrato (si las partes no fijaran el plazo, es anual conforme la norma supletoria del Art. 17 Ley de Seguros) y no sólo el correspondiente a un período determinado (el que dure la cuarentena obligatoria). Su percepción en cuotas es una modalidad que favorece el pago por parte del deudor al diferirlo por la existencia de plazos y mejora el cumplimiento en favor del acreedor. No debe soslayarse, sin embargo, que la prima en materia de seguro automotor es técnicamente insuficiente desde hace muchos años y el déficit sólo era enjugado durante todo este tiempo por el superávit financiero, que es justamente lo que se ha visto afectado por la caída general en la actividad del país y la pérdida de valor de los títulos públicos que constituyen buena parte de los activos de las aseguradoras ${ }^{22}$.

entidades aseguradoras y/o Productores Asesores de Seguros respecto de las coberturas ofrecidas y/o medios y/o modalidades de pago vigente" (https:/www.argentina.gob.ar/noticias/comunicado-sobre-elseguro-de-vehiculos-automotores-yo-remolcados).

21 https://www.clarin.com/economia/economia/baja-siniestralidad-aseguradoras-aceptan-reclamosreducir-cuotas-polizas_0_m1UeFE50E.html.

22 Existe una iniciativa legislativa del diputado cordobés Pablo Carro que propone que las compañías aseguradoras reintegren a los usuarios parte de lo abonado en el seguro automotor obligatorio. El proyecto de ley se fundamenta en la baja siniestralidad registrada en el marco de la pandemia y solicita al Poder Ejecutivo Nacional que, a través de la Superintendencia de Seguros de la Nación, disponga el reintegro parcial por parte de las compañías aseguradoras del costo de la cobertura del seguro automotor obligatorio en el período de la cuarentena. Sin embargo, el parlamento argentino se encuentra paralizado desde el establecimiento del aislamiento y no han podido funcionar en forma remota hasta la fecha. 
Nos ocuparemos más delante de delinear las soluciones que contempla la ley de seguros argentina en materia precisamente de disminución del riesgo.

\section{LA REACCIÓN DEL SISTEMA DE SEGURO DE RIESGOS DEL TRABAJO}

Resulta previsible que en el sistema de Riesgos del Trabajo habrá una menor siniestralidad por la caída de la actividad y que por la desocupación habrá menores ingresos para hacer frente a los siniestros y al stock ya existente derivado de la alta litigiosidad en la materia. El Poder Ejecutivo, mediante Decreto de Necesidad y Urgencia 367/2020, estableció que el COVID-19 podrá ser considerado presuntivamente enfermedad de carácter profesional no listada y, por lo tanto, su cobertura no podrá ser rechazada por las Asegurados de Riesgos del Trabajo para aquellos trabajadores que realicen actividades exceptuadas del aislamiento social preventivo obligatorio (esenciales) y que resulten a consecuencia de ello contagiados. Agrega que en el caso del personal del servicio de salud se presumirá la vinculación directa entre la actividad y el covid-19, salvo prueba en contrario. Se establece un plazo de 60 días de finalizada la emergencia en materia sanitaria, dentro del cual los casos podrán ser imputados al Fondo Fiduciario de Enfermedades Profesionales (FFEP).

Las aseguradoras ante la denuncia del trabajador deberán brindarle las prestaciones correspondientes y el Cuerpo Médico Central será quien tendrá a su cargo la confirmación del carácter profesional del contagio. La norma será de aplicación a las contingencias cuya primera manifestación invalidante haya sido a partir de la entrada en vigencia de la cuarentena (20.03.20).

La inclusión del COVID-19 como enfermedad profesional podría tener un impacto negativo sobre la solvencia del sistema, por cuanto tal enfermedad no fue contemplada al momento de cotizar la alícuota o precio del seguro que pagan todos los empleadores y existe incertidumbre respecto de la suficiencia del Fondo, dado que el aporte que efectúan los empleadores mensualmente por trabajador no fue actualizado desde el año 1997, a pesar de la inflación reinante.

\section{LA CUESTIÓN EN LOS SEGUROS PATRIMONIALES}

En materia de seguros que cubren los daños a la propiedad: seguros de incendio, combinado familiar, integral de comercios, todo riesgo operativo, avería de maquinaria y construcción, no presentan exclusiones relacionadas con la transmisión de enfermedades, ni con la ocurrencia de pandemias. En cambio, esas exclusiones suelen existir en otras líneas como son los seguros de responsabilidad civil comprensiva, responsabilidad civil profesional, líneas financieras, o de cancelación de eventos.

En la cobertura de pérdida de beneficios e interrupción de negocios es habitual que sea otorgada en forma adicional y condicionada a la existencia de daños materiales o físicos sufridos por los bienes asegurados. En principio, el virus no provoca daños 
físicos ni materiales a superficies, instalaciones, propiedades u objetos asegurados, aunque la cuestión empieza a generar polémica en el mundo.

Adicionalmente, es frecuente que se incluya una exclusión de cobertura por pérdidas causadas por paralización, demoras o pérdida de negocios a consecuencia de órdenes o disposiciones de la autoridad pública, como es el caso de la normativa reseñada más arriba.

Por cierto, en uno y otro caso, resulta indispensable acudir en primer lugar al texto de la cobertura para conocer la verdadera extensión del riesgo cubierto y de lo excluido expresa o implícitamente.

A lo expuesto, cabe agregar que, como consecuencia de las medidas que está tomando la autoridad pública del país, pueden producirse cambios materiales en el estado del riesgo cubierto, que puede ser diferente para cada asegurado.

Un ejemplo sería que el riesgo cubierto quede sin personal de custodia por periodos prolongados, aumentando el álea de robo y demorando la posible detección de un inicio de incendio. Otros ejemplos comunes serían el aumento de stocks y carga de fuego, por cambios en las ventas materias primas, o en los procesos logísticos de su distribución; o la reducción del mantenimiento de los equipos críticos o de seguridad, que determine su inoperancia en caso de necesidad.

Muy considerable es, asimismo, el crecimiento de la exposición a riesgos de Cyber por el aumento del teletrabajo, sin haber implementado, por falta de tiempo, medidas de seguridad adecuadas. En este aspecto, resulta visible que el fraude cibernético no descansa.

Sabido es que en materia de agravación del riesgo por hecho ajenos al asegurado es carga de éste notificar a su asegurador cualquier cambio del álea respecto de las condiciones existentes con relación a lo cubierto al momento de la contratación que hubieran modificado las condiciones de la póliza o determinado que el asegurador no de la cobertura (Art. 37 Ley $\mathrm{N}^{\circ}$ 17.418).

Si bien es cierto que muchas de esas modificaciones serán de público conocimiento por lo que el asegurador no podrá alegar su desconocimiento, sin embargo, también algunas pueden afectar a cada asegurado en forma particular y con relación a ellas regirá la carga del asegurado de comunicarlas al asegurador, y su incumplimiento generará al momento del siniestro, la caducidad de derechos del asegurado, si su incumplimiento obedeciera a su culpa o negligencia y no pudiera acreditar el conocimiento del asegurador.

Un ejemplo de esto sería la interrupción del mantenimiento del sistema de bombas de un sistema de rociadores contra incendio, en el que se discontinuó el mantenimiento semanal que se hacía normalmente siguiendo normas internas, y que al momento de un incendio falla. Si el asegurado notificó el cambio en el procedimiento en forma oportuna no tendría problemas de cobertura, en cambio sí omitió hacerlo podría derivar en un conflicto al momento del siniestro.

Cuando el agravamiento sea leve y razonable, una vez comunicado por el asegurado, la aseguradora se dará por notificada sin consecuencias relevantes en la cobertura. En cambio, si fueran de envergadura, la aseguradora podrá hacer sugerencias para mitigar el riesgo, o disponer aumentos de prima (por mayor productividad, por ejemplo, en el 
caso de una fábrica de respiradores que duplicó su producción), o en casos extremos de modificación del riesgo, como el de cambia su actividad y se dedica a la fabricación y venta de alcohol en gel, la aseguradora podría rescindir la cobertura (en los plazos previstos, Art. 39 Ley $\mathrm{N}^{\circ}$ 17.418).

Nos ocuparemos más delante con mayor detalle de las soluciones que contempla la ley de seguros argentina en materia agravamiento del riesgo.

\section{EL COVID-19 EN LOS SEGUROS DE PERSONAS}

Con relación a los seguros de personas, si bien hay una proporción importante de coberturas que no presentan la exclusión de pandemia (así lo reconoció tempranamente AVIRA, la Cámara que nuclea a las aseguradoras del riesgo de vida) ${ }^{23}$, otras si la incluyen expresamente, así como los supuestos más focalizados de transmisión de enfermedades denominados epidemias.

¿Se justifica en una cobertura asegurativa la exclusión de pandemia? La respuesta es afirmativa: el seguro técnicamente se funda en un cálculo de probabilidades, esto es, la relación entre el número de chances de realización de un evento dañoso sobre el número de casos posibles. Por su parte, la frecuencia está constituida por la relación existente entre el número de resultados obtenidos y el número de experiencias consideradas y, finalmente, toma en consideración su costo medio o entidad de la prestación. La compañía de seguros debe prever el número de siniestros que habrán de verificarse con relación a los riesgos asegurados, la regularidad con que acontecerán y su costo medio para poder calcular el valor de la prima suficiente para que abone la mutualidad de asegurados de riesgos homogéneos y dispersos ${ }^{24}$.

Los riesgos catastróficos, como una pandemia, por su especificidad, resultan de difícil encuadre en la técnica actuarial descripta y requerirían, en principio, primas mucho más elevadas de las que están previstas.

Nada impedirá seguramente en el futuro que este riesgo sea tomado a través del pago de una extraprima.

\section{LA AGRAVIÓN Y DISMINUCIÓN DEL RIESGO EN LA LEY DE SEGUROS}

Sabido es que el riesgo constituye el objeto del contrato de seguro y que se trata de un elemento fundante de las relaciones entre asegurado y asegurador. Se lo define como la probabilidad de que acontezca el hecho futuro e incierto previsto en el contrato. Para que ese hecho futuro e incierto sea entendido como un siniestro es necesario que las condiciones previstas en el contrato se mantengan constantes e invariables durante

\footnotetext{
${ }^{23}$ ZanATTA, Mauricio, presidente de Avira, en http://www.todoriesgo.com.ar/zanatta-la-gran-mayoriade-los-productos-ofrecidos-por-las-companias-que-integran-avira-no-excluyen-al-covid19/.

24 Stiglitz, Rubén S. Derecho de Seguros, tomo I, 5ta. Ed. act. y ampl., La Ley, 2008, p. 10.
} 
el tiempo de esa ejecución contractual ${ }^{25}$. Sin embargo, el mantenimiento del estado del riesgo no es un concepto rígido o inflexible, sino que atiende tanto a la regularidad de las modificaciones en el mismo que devienen previsibles como a las que acontezcan en forma inverosímil, casual o imprevisible (la pandemia).

El mantenimiento del estado del riesgo interesa no sólo al asegurador, ya que habrá contratado teniéndolo en cuenta para tomar o no el riesgo y parar fijar la prima; sino también a la masa de asegurados, ya que su alteración podría significar un aumento de la probabilidad del siniestro y, con ello, una eventual imposibilidad económica del asegurador de atender los siniestros ${ }^{26}$.

En atención a la necesidad de prevención del riesgo, la ley de seguros argentina impone al asegurado tres cargas fundamentales: a) la de declarar lo más exactamente posible el riesgo asegurado, cuya violación culpable o dolosa genera la nulidad del contrato (Art. 5 de la Ley $\mathrm{N}^{\circ} 17.418$ que regula el instituto de la reticencia); b) la de mantener el estado de riesgo y denunciar su agravación, cuyo incumplimiento es causa de rescisión del contrato (Art. 37 Ley $\mathrm{N}^{\circ}$ 17.418); en ambos casos, la sanción debe ponderarse de acuerdo a la prueba tasada legal: si a juicio de peritos el hecho sobreviniente hubiera impedido el contrato o modificado sus condiciones; c) la carga de salvamento, por la que el asegurado debe proveer lo necesario, en la medida de sus posibilidades para precaver el siniestro o disminuir el daño, y observar las instrucciones del asegurador, a esos fines (Art. 72 LS).

En cuanto a la oportunidad de cumplimiento de las referidas cargas, mientras la primera exhibe su relevancia a la época de la contratación del seguro y, por ello, es una carga precontractual, previa y simultánea al nacimiento del contrato; la segunda, en cambio, es debida durante todo el término de vigencia contractual; por último, la carga de salvamento, nace aún ante la inminencia del siniestro y perdura mientras exista la probabilidad de daño.

En la ley de Seguros argentina se alienta al asegurado en la tarea de prevención del siniestro o morigeración de sus consecuencias a través de lo previsto por el Art. 43 de la Ley $\mathrm{N}^{\circ} 17.418$ en cuanto las disposiciones sobre agravación del riesgo no se aplican cuando se provoque el daño para precaver el siniestro o atenuar sus consecuencias o por un deber de humanidad generalmente aceptado.

La sanción que prevé la normativa argentina ante la agravación del riesgo producida por un hecho del asegurado o ajeno a él, que a juicio de peritos hubiera impedido el contrato o modificado sus condiciones ${ }^{27}$, es la rescisión, la que debe ser comunicada por el asegurador al asegurado dentro del plazo que designa la ley según se trate de un agravamiento por un hecho del propio tomador o asegurado, o ajeno a él.

\footnotetext{
${ }^{25}$ Halperín, Isaac, ob. cit., p. 560.

26 Roitman, Horacio; Aguirre, Felipe F. La agravación del riesgo en el contrato de seguro, $2^{\circ}$ ed. Buenos Aires: Abeledo Perrot, 2012, p. 5.

27 Aguirre, Felipe F. "El juicio de peritos". En: la Ley de Seguros, RCyS2014-II, 189, cita Online: AR/DOC/3756/2013.
} 
Si la agravación obedeció a un hecho propio del asegurado o tomador, la garantía queda suspendida desde la comunicación que efectúe el asegurado antes que el hecho se produzca (Art. 38) y el asegurador debe comunicar su decisión de rescindir dentro del plazo de siete días (Art. 39). Lo propio acontece cuando el asegurador no hubiera asumido el riesgo según sus prácticas comerciales.

En cambio, si la agravación del riesgo se debió a un hecho ajeno al asegurado o tomador, el asegurador debe notificar su decisión de rescindir dentro del plazo de 30 días de la denuncia inmediata que debe hacer el asegurado (Art. 38), con un preaviso de siete días (Art. 39). Lo propio acontece, por su parte, cuando el asegurado hubiera debido permitir la agravación o provocarla por razones ajenas a su voluntad (Art. 40). El derecho de rescisión del asegurador se extingue si no lo ejerce dentro de los plazos previstos en la norma o si la agravación del riesgo hubiera desaparecido (Art. 42).

El Art. 45 prevé la hipótesis de que el contrato comprenda una pluralidad de intereses o personas y la agravación sólo afecte a una parte de ellos, el asegurador podrá rescindir todo el contrato, si no lo hubiere celebrado en las mismas condiciones respecto de los no afectados. Recíprocamente, si el asegurador sólo rescinde parcialmente el contrato, el asegurado puede rescindirlo totalmente.

En caso de siniestro, si el asegurado omite denunciar la agravación, el asegurador no se encuentra obligado a su cobertura si se produce durante la subsistencia de aquélla, excepto que el tomador incurriera en la omisión o demora sin culpa o negligencia o si el asegurador conocía la agravación al tiempo en que debía hacérsele la denuncia (Art. $40,2^{\circ}$ ).

En cuanto al incumplimiento de la carga de salvamento sólo opera en caso de su violación dolosa o por culpa grave y resulta en que el asegurador queda liberado de su obligación de indemnizar en la medida que el daño habría resultado menor si no se hubiera verificado tal violación (Art. 72, 2do. párrafo, LS).

La carga de la prueba pesa sobre el asegurador que alega el incumplimiento de la carga por el asegurado y comprende tanto la de los hechos que constituyen el agravamiento del riesgo, como la de su relevancia a los efectos que prevé el Art. 37 de la Ley $\mathrm{N}^{\circ} 17.418 .{ }^{28}$ Ese principio no se encuentra excepcionado, conforme la opinión mayoritaria ${ }^{29}$, por la circunstancia que en la póliza se haya descripto el hecho como causal de agravamiento del riesgo porque ello violaría tanto el Art. 158 de la Ley $\mathrm{N}^{\circ}$ 17.418 (que sólo permite la modificación del Art. 37 en favor del asegurado), como por el Art. 37, inc. c) de la Ley $\mathrm{N}^{\circ} 24.240$ de defensa de los consumidores y usuarios, en tanto constituiría una cláusula abusiva prevista específicamente (la inversión de la carga de la prueba en perjuicio del consumidor o usuario).

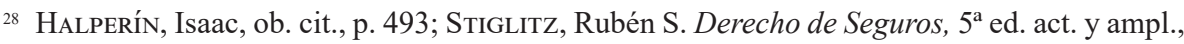
La Ley, Bs. As. 2008, t. II, nro. 686, p. 118.

${ }^{29}$ Morandi, Juan C. F. El riesgo en el contrato de seguro. Régimen de modificaciones que lo agravan, Buenos Aires: Astrea, 1974, p. 43, p. 146; Roitman, Horacio-Aguirre, Felipe F. ob. cit., p. 61; CNCom, Sala D, 12.04.00, “Torga, Adela c/ Generali Cía. de Segs., ED 191-139.
} 
En cuanto a la prima, cuando el asegurador optase por no rescindir el contrato o la rescisión fuese improcedente, corresponderá el reajuste de la prima de acuerdo al nuevo estado del riesgo desde la denuncia, según la tarifa aplicable en este momento (Art. 35 LS). Si opta, en cambio, por la rescisión, en caso que la agravación fuese comunicada oportunamente, el asegurador tiene derecho a percibir la prima proporcional al tiempo transcurrido; mientras que, si la denuncia fuese tardía, tiene derecho a percibir la prima por el período en curso (Art. 41 LS).

A la inversa, cuando el riesgo ha disminuido el asegurado tiene derecho al reajuste de la prima por los períodos posteriores, conforme a la tarifa aplicable al tiempo de la denuncia de la disminución (Art. 34 LS). Es desde el momento de la denuncia efectuada por el asegurado que el asegurador deja de responder por el riesgo original.

La solución se explica tanto en el supuesto de agravación como de disminución del riesgo en el denominado principio de indivisibilidad de la prima: es debida íntegramente al asegurador desde el momento de la asunción del riesgo sin que la producción del siniestro otorgue derecho al asegurado al reembolso de aquél y se explica porque como esbozamos más arriba son calculadas por períodos enteros y, por tanto, quedarían desvirtuados los cálculos del asegurador para afrontar los riesgos de la cartera de clientes ${ }^{30}$.

\section{LOS REMEDIOS DEL DERECHO PRIVADO FRENTE A UN EVENTO FORTUITO}

Si bien en el contrato de seguro las obligaciones de las partes se traducen en sumas de dinero y como obligaciones de género, no perecen, lo cierto es que no puede desconocerse que la declaración de la pandemia por covid-19 y las medidas gubernamentales que tienen por objeto contener el contagio entre las personas pueden ser entendidas como supuestos de caso fortuito o fuerza mayor. En este sentido, el Tribunal de Apelación de Colmar acaba de dictaminar un caso como de fuerza mayor para la epidemia COVID-1931.

El contrato de seguro establece relaciones jurídicas que se extienden por cierto tiempo, cuyo desarrollo fluye en él, con un plazo determinado, y a veces con natural vocación de perduración futura a través de la renovación de la cobertura. Emergencia como las que atravesamos en este momento generan imposibilidades fácticas y, en el plano jurídico, un régimen de excepción con el que deben lidiar las legítimas expectativas de las partes contratantes ${ }^{32}$.

El Código Civil y Comercial de la Nación, vigente desde el $1^{\circ}$ de agosto de 2015 proporciona en una pluralidad de normas soluciones aplicables en materia contractual.

\footnotetext{
${ }^{30}$ Stiglitz, Rubén S., ob. cit., tomo III, Nº. 982, p. 15.

${ }^{31}$ Colmar, 6to. Cap., 12 de marzo de 2020, n ${ }^{\circ} 20 / 01098$.

${ }_{32}$ Rivera, Julio César. "Los contratos frente a la pandemia", LA LEY 22/04/2020, p. 8, cita Online: AR/DOC/1102/2020.
} 
El Art. 955 establece que la imposibilidad sobrevenida, objetiva, absoluta y definitiva de la prestación, producida por caso fortuito o fuerza mayor, extingue la obligación establecida en el contrato a cargo de una de las partes, sin responsabilidad. Es claro que, si la imposibilidad sobrevino debido a causas imputables al deudor, como ocurriría si se encontraba ya en mora al momento de ponerse en vigencia las normas restrictivas de la actividad en función de la atención de la población frente a la pandemia, la obligación se convertirá en la de indemnizar los daños derivados del incumplimiento, salvo que la mora fuera irrelevante.

Si la imposibilidad es temporaria, la imposibilidad sobrevenida, objetiva, absoluta y temporaria de la prestación objeto de la obligación nacida del vínculo contractual tendrá efecto extintivo cuando el plazo sea esencial o cuando su duración frustra el interés del acreedor de modo irreversible (Art. 1090). La finalidad afectada debe ser esencial, en el sentido que de no alcanzársela, la parte que contrató en consideración a ese resultado vería malogrado su interés ${ }^{33}$, como por ejemplo, en los seguros de personas, el caso del silletero que tenía contratado un seguro de accidentes personales por un plazo de un mes para realizar un trabajo de limpieza en altura que fuera cancelado.

En cuanto a la imprevisión, es claro que las medidas dispuestas por la autoridad pública durante esta pandemia pueden constituir la "alteración extraordinaria de las circunstancias existentes al tiempo de su celebración, sobrevenida por causas ajenas a las partes y al riesgo asumido por la que es afectada" que, al generar una excesiva onerosidad, permiten plantear la adecuación o la resolución parcial o total de los contratos conmutativos o aleatorios -en este caso, cuando la excesiva onerosidad proviene de factores ajenos al alea propia del contrato-, de ejecución diferida o permanente. La solución resulta por tanto aplicable al contrato de seguro (Art. 1091).

A diferencia de los que ocurría en el Código Civil Velezano, en el que la parte afectada podía plantear la resolución y quedaba al arbitrio de la otra el ofertar un reajuste de las pretensiones, en el régimen actual también el obligado que enfrenta un desequilibrio derivado de la mayor onerosidad generada por un factor ajeno puede plantear la adecuación del contrato ${ }^{34}$.

También puede darse la aplicación la suspensión del propio cumplimiento si sus derechos sufriesen una grave amenaza de daño porque la otra parte sufrió un menoscabo significativo en su aptitud para cumplir, o en su solvencia; suspensión que queda sin efecto cuando la otra parte cumple o da seguridades suficientes de que el cumplimiento será realizado (Art. 1032). Esta prerrogativa deberá ser ejercida con sujeción a los principios generales de buena fe y ejercicio no abusivo del derecho (Arts. 9 y 10).

Además, pues de los remedios propios del sistema dispuesto por la ley especial, resultarían de aplicación los previstos en el Código de fondo y que reseñamos brevemente.

${ }_{33}$ Stiglitz, Rubén S. Frustración del fin del contrato, cita Online: 0003/000628.

${ }^{34}$ AlterinI, Atilio Aníbal. Los principios sobre los contratos de UNIDROIT y las soluciones del derecho común, DJ1997-2, 1055, cita Online: AR/DOC/13360/2001. 


\section{ALGUNAS CONCLUSIONES PROVISIONALES}

Por cierto, los efectos de la pandemia en el Derecho de Seguros se harán sentir y se extenderán prácticamente a la mayor parte de los ramos cubiertos por el seguro. Si bien en nuestro país han sido numerosas las crisis económicas, la actual pandemia genera una situación de complejidad inusitada ya que se desconocen aún la extensión temporal y la de las consecuencias que producirá.

En ese contexto, urge adoptar criterios que permitan mantener la vigencia de los contratos, adaptar las soluciones a la mejor consecución de los fines que tuvieron las partes al contratar, dentro de un marco de razonabilidad.

En ese derrotero, además de los remedios propios dispuestos por la ley especial, resultarán de aplicación los previstos en el Código de fondo, con sujeción a los principios generales de buena fe y ejercicio no abusivo del derecho.

\section{BIBLIOGRAFÍA}

Aguirre, Felipe F. "El juicio de peritos". En: Ley de Seguros, RCyS2014-II, 189, cita La Ley Online: AR/DOC/3756/2013.

AlterinI, Atilio Aníbal. "Los principios sobre los contratos de UNIDROIT y las soluciones del derecho común”, DJ1997-2, 1055, cita La Ley Online: AR/DOC/13360/2001.

Alterini, Atilio A.; Ameal, Oscar J. y López Cabana, Roberto M. "Derecho de obligaciones civiles y comerciales", 4 a ed. act., nro. 510, Buenos Aires: Abeledo Perrot, 2008.

BARBATo, Nicolás. Exclusiones a la cobertura en el contrato de seguro, ED 136-547.

Compiani, María Fabiana. "El seguro frente a la pandemia", columna de opinión, La Ley del 20.04.20.

Compiani, Maria Fabiana. "Las exclusiones de cobertura en el seguro automotor", RCyS, 2015, III, 225.

HALPERÍn, Isaac. “Seguro”, $3^{\mathrm{a}}$ ed. actual. y ampl. por Barbato, Nicolás H., Buenos Aires: Depalma.

Morand, Juan C. F. El riesgo en el contrato de seguro. Régimen de modificaciones que lo agravan, Buenos Aires: Astrea, 1974.

Piaggio, Aníbal N. "Azar y certeza en derecho de daños”, especialmente nota 42, ED del 10/5/1993.

Rivera, Julio César. "Los contratos frente a la pandemia”, LA LEY 22/04/2020. Cita Online: $\mathrm{AR} / \mathrm{DOC} / 1102 / 2020$.

Roitman, Horacio-Aguirre, Felipe F. La agravación del riesgo en el contrato de seguro, $2^{\circ}$ ed. Buenos Aires: Abeledo Perrot, 2012.

Stiglitz, Rubén S. "La inaplicabilidad del análisis de la relación causal a las exclusiones de cobertura fundadas en actos ilícitos del asegurado", LL 2010-E-999, y por el mismo autor, "Seguro contra la responsabilidad civil y el riesgo automotor", LL 2013-D-1017.

Stiglitz, Rubén S. Derecho de Seguros, tomo I, 5ta. Ed. act. y ampl., La Ley, 2008.

StigLitz, Rubén S. Frustración del fin del contrato, cita La Ley Online: 0003/000628. 